\title{
MODELING STUDIES OF BI- AND QUAD-WING FLAPPING ORNITHOPTER KINEMATICS AND AERODYNAMICS
}

\author{
H. Djojodihardjo and A. S. S. Ramli \\ Department of Aerospace Engineering, Faculty of Engineering \\ Universiti Putra Malaysia, 43400 UPM Serdang, Selangor, Malaysia. \\ Email: harijono@djojodihardjo.com \\ Phone: $+60174169045 ;+628159301745$ \\ Email: alifsyamimsyazwan@yahoo.com
}

\begin{abstract}
Following an earlier attempt to develop a generic approach to model the kinematics and aerodynamics of a bi-wing flapping wing ornithopter, modeled following a simplified version of DeLaurier's approach with appropriate modifications, a flapping quad-wing ornithopter kinematic and aerodynamic model is also developed. Consideration is given to the motion of a rigid and thin bi-wing and quad-wing ornithopter in flapping and pitching motion with phase lag. A basic unsteady aerodynamic approach incorporating salient features of viscous effect and leading-edge suction is utilized. A parametric study is carried out to reveal their aerodynamic characteristics and for comparative analysis with various selected simple models in the literature. In spite of their simplicity, the results obtained for both models are able to reveal the mechanism of lift and thrust, and compare well with other works.
\end{abstract}

Keywords: flapping wing aerodynamics; flapping wing ornithopter; micro air vehicle; quad-wing ornithopter; bi-wing ornithopter.

\section{INTRODUCTION}

Human efforts to mimic flying biosystems such as insects and birds through engineering feats to meet human needs have progressed for hundreds of years as well as motivated mankind's creativity, from Leonardo Da Vinci's drawings to Otto Lilienthal's gliders, to modern aircraft technologies and present flapping flight research. Recent interest in the latter has grown significantly particularly for small flight vehicles (or micro-airvehicles) with very small payload-carrying capabilities to allow remote sensing missions where access is restricted due to various hazards. Some of these vehicles may have a typical wingspan of $15 \mathrm{~cm}$, with a weight restriction of less than $100 \mathrm{~g}$ (Ho, Nassef, Pornsinsirirak, Tai, \& Ho, 2003). The generic train of thought in modeling and developing an up and down flapping motion configuration with flexible membrane wing skins can be summarized in Figure 1. Perhaps the most comprehensive account of insect flight or the entomopter to date is given by (Ellington, 1984, 1999), Dickinson, Lehmann, and Sane (1999) and Ansari, Żbikowski, and Knowles (2006), while one of the first successful attempts to develop bird-like flapping flight was made by DeLaurier (1993). The flapping wing designs have been created with varied success, for either forward or hover mode, but not both, based on observations of hummingbirds and bats. According to entomologists, the dragonfly has the capability to shift flight modes simply by varying the phase lag between its fore and hind wings (Maybury \& Lehmann, 
2004). With that observation, a quad-winged flapping system could be conceived as the simplest mechanism that has the capabilities to shift between flights modes. In one of the recent works in developing a quad flapping wing micro air vehicle, Ratti (2011) has theoretically shown that a flight vehicle with four flapping wings has $50 \%$ higher efficiency than one with two flapping wings. Inspired by the flight of a dragonfly, (Prosser, 2011) analyzed, developed and demonstrated a quad-winged air vehicle (QWAV) which can produce higher aerodynamic performance and energy efficiency, and has increased payload capacity compared to a conventional (flapping wing) MAV.

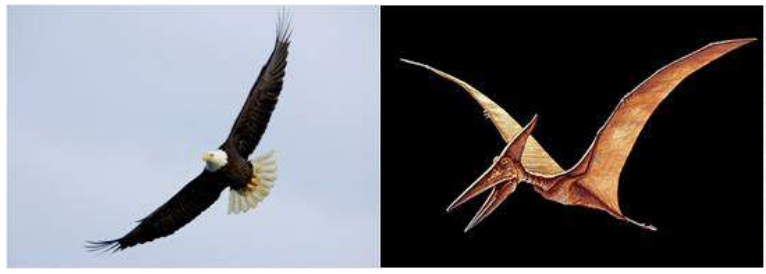

(a)(b)

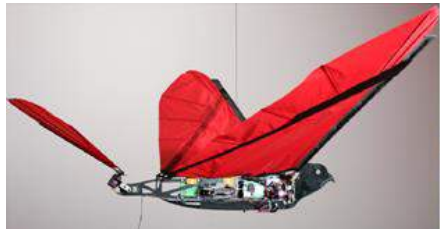

(e) (c)

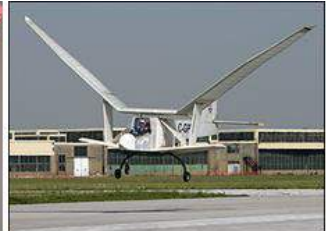

(f)

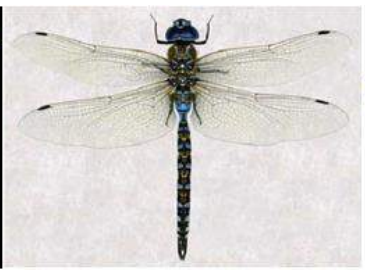

(d)

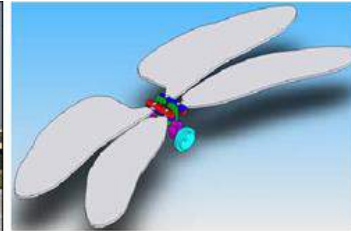

(g)
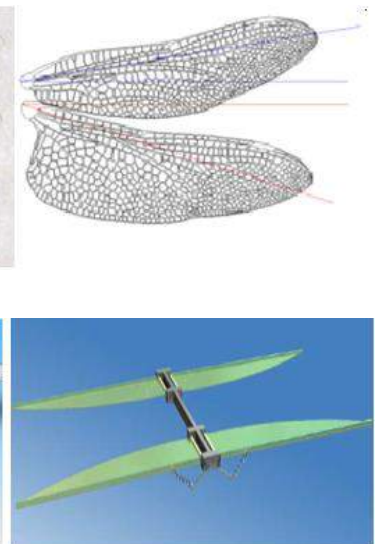

(h)

Figure 1. Comparison of flying biosystems and their modeling as a flapping wing ornithopter and quad-wing air vehicle (QWAV); (a) soaring eagle exhibiting its wing

geometry and structural detail, (b) pterosaur (Strang, 2009) exhibiting its generic structure, (c) a dragonfly. and (d) its wings (Nicholson, Page, Dong, \& Slater, 2007),

(e) Jackowski (2009) Ornithopter as a functioning model, (f) DeLaurier (1993)

Ornithopter as a large scale mechanized ornithopter, (g) ((Nicholson et al., 2007), and

(h) models of quad-wing air vehicle (Prosser et al., 2011).

Against this backdrop, in the present work, a generic approach is followed to understand and mimic the unsteady aerodynamics of bio-inspired QWAV, preceded by an attempt to develop a pterosaur-like ornithopter to produce lift and thrust for forward flight and hence develop a simple and workable micro-air-vehicle (MAV) ornithopter flight model. At this stage, such a model does not need to incorporate the more involved leading edge vortex and wake penetration exhibited by insect flight (Ellington, 1984, 1999). As elaborated successively, the novel approach adopted in this work is in developing the first and second generic and simplified approach for the analysis of biand quad-wing, the separation of the flapping and pitching contributions to the aerodynamic forces, and the presentation of the results, among others. A parametric study assists analysis, and provides insight and optimization by inspection. 
Table 1. Overview of some relevant characteristics of flapping biosystems.

\begin{tabular}{|c|c|c|c|c|c|c|c|}
\hline Items & Insects & $\begin{array}{l}\text { Hummi } \\
\text { ng bird }\end{array}$ & Bat & $\begin{array}{l}\text { Small } \\
\text { birds }\end{array}$ & $\begin{array}{l}\text { Large } \\
\text { birds }\end{array}$ & $\begin{array}{l}\text { Flappin } \\
\text { g MAV }\end{array}$ & $\begin{array}{l}\text { Small low } \\
\text { speed } \\
\text { airplanes }\end{array}$ \\
\hline 1. Types & $\begin{array}{l}\text { Beetles, } \\
\text { bumblebees, } \\
\text { butterflies, } \\
\text { dragonflies, }\end{array}$ & $\begin{array}{c}\text { Amazil } \\
\text { ia }\end{array}$ & $\begin{array}{c}\text { PlecotusAuritu } \\
\text { s }\end{array}$ & $\begin{array}{l}\text { Sparrows } \\
\text {, swifts, } \\
\text { robins }\end{array}$ & $\begin{array}{l}\text { Eagle, } \\
\text { hawk, } \\
\text { vulture, } \\
\text { falcon, } \\
\text { skua gull }\end{array}$ & $\begin{array}{l}\text { DARP } \\
\text { A DRO }\end{array}$ & $\begin{array}{c}\text { Cessna } \\
210\end{array}$ \\
\hline $\begin{array}{l}\text { 2. Weight } \\
\text { typical (gf) }\end{array}$ & $\begin{array}{c}25 \times 10^{-5}- \\
12.8\end{array}$ & 5.1 & 9.0 & $35-82$ & $952-4300$ & $\leq 50$ & 1045000 \\
\hline $\begin{array}{l}\text { 3. Wing semi- } \\
\operatorname{span}^{(\mathrm{cm})^{1}}\end{array}$ & $0.062-7.7$ & 5.9 & 11.5 & $20-48$ & $58-102$ & $<7.5$ & 5600 \\
\hline $\begin{array}{l}\text { Wing-loading } \\
\left(\mathrm{g} / \mathrm{cm}^{2}\right)\end{array}$ & $10^{-3}-10^{-1}$ & 0.4 & 0.072 & $\begin{array}{c}0.029 \\
0.152\end{array}$ & $0.35-0.67$ & $10^{-2}-1$ & 11.18 \\
\hline $\begin{array}{l}\text { 4. Typical } \\
\text { power (gf cm } \\
\sec ^{-1} \text { per gf) }\end{array}$ & $5.3-238$ & 130 & 83 & $93-110$ & $42-57$ & $\approx 39$ & $\approx 1.3 \times 10^{4}$ \\
\hline $\begin{array}{l}\text { 5. Dominant } \\
\text { wing } \\
\text { movement }\end{array}$ & Hover & $\begin{array}{l}\text { Hover } \\
\text { and fly }\end{array}$ & Fly & Fly & Fly & $\begin{array}{l}\text { Hover } \\
\text { and fly }\end{array}$ & Fly \\
\hline $\begin{array}{c}\text { 6. Flight } \\
\text { speed }(\mathrm{m} / \mathrm{s})\end{array}$ & $1.05-9$ & 15 & $10-14$ & $6-10$ & $10-20$ & $3-10$ & $\begin{array}{c}99 \mathrm{~m} / \mathrm{s} \\
\text { (cruise at } \\
6100 \mathrm{~m} \\
\text { altitude) }\end{array}$ \\
\hline $\begin{array}{l}\text { 7. Reynolds } \\
\text { No. }\end{array}$ & $10-1000$ & 7500 & 14000 & $10^{3}-10^{4}$ & $10^{4}-10^{5}$ & $\begin{array}{c}10^{4}- \\
10^{5}\end{array}$ & $\begin{array}{c}10,000,00 \\
0\end{array}$ \\
\hline $\begin{array}{l}\text { 8. Leading } \\
\text { edge } \\
\text { vortex/LEV }\end{array}$ & $\begin{array}{c}\text { LEV by } \\
\text { swept wing } \\
\text { at } \operatorname{Re}=5 \times \\
10^{3}\end{array}$ & yes & yes & yes & yes & yes & no \\
\hline $\begin{array}{l}\text { 10. Entering } \\
\text { its own TEV/ } \\
\text { Wake capture }\end{array}$ & yes & yes & no & no & no & no & no \\
\hline $\begin{array}{l}\text { 9. Laminar } \\
\text { separation } \\
\text { bubble/LSB }\end{array}$ & yes & yes & yes & yes & yes & yes & no \\
\hline $\begin{array}{l}\text { 10. Leading } \\
\text { edge flap }\end{array}$ & - & - & $\begin{array}{c}\text { Has been } \\
\text { observed on } \\
\text { bats }\end{array}$ & - & $\begin{array}{c}\text { e.g. } \\
\text { Mallard, } \\
\text { at } \operatorname{Re}=6 \times \\
10^{4}\end{array}$ & - & - \\
\hline $\begin{array}{c}\text { 11. Self- } \\
\text { activated flaps } \\
\text { at TE }\end{array}$ & & & & & $\begin{array}{l}\text { e.g. skua } \\
\text { gull }\end{array}$ & & \\
\hline
\end{tabular}

${ }^{1}$ Power functions of wing dimensions and flight parameters against body mass $m$, following Shyy, Berg, and Ljungqvist (1999) and Norberg (1970). The exponent of correlation is for (Mass) exponent $^{\text {end }}$ 


\section{LEARNING FROM NATURE - OBSERVATION AND CHARACTERIZATION}

In view of these findings, the classification tabulated in Table 1 summarizes some of the relevant features of flapping biosystems that may give us an overview in developing a flapping ornithopter MAV. A biosystem's flapping flights are characterized by relatively low Reynolds number, flexible wing, highly unsteady flow, laminar separation bubble, non-symmetrical upstroke and downstroke and, for entomopters, the presence and significant role of the leading edge vortex, and wake vortices capture, among others. Birds habitually perform aerial maneuvers that exceed the capabilities of the best anthropogenic / man-made aircraft control systems (Tedrake et al., 2009). The complexity and variability of the aerodynamics during these maneuvers are difficult, with dominant flow structures (e.g., vortices) that are difficult to predict robustly from first-principles (or Navier-Stokes) models. In this conjunction, machine learning will play an important role in the control design process for responsive flight by building data-driven approximate models of the aerodynamics and by synthesizing highperformance nonlinear feedback laws based on these approximate models and trial-anderror experience.

\section{KINEMATICS OF FLAPPING WING MOTION}

The flapping wing motion of ornithopters and entomopters can be generally grouped in three classes, based on the kinematics of the wing motion and mechanism of forces generation; the horizontal stroke plane, inclined stroke plane and vertical stroke plane (Ellington, 1984).

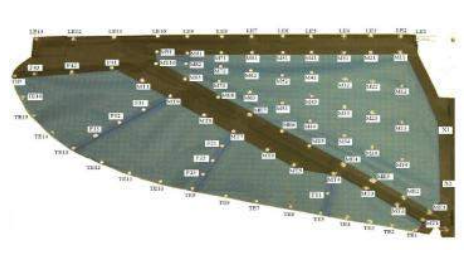

(a)(b)

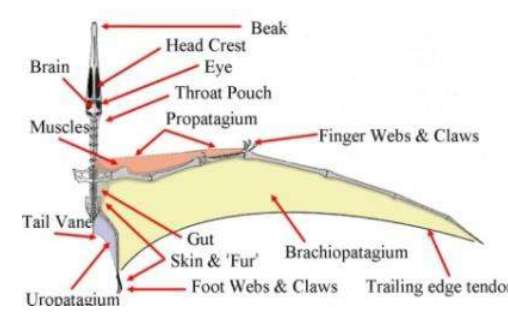

(d)

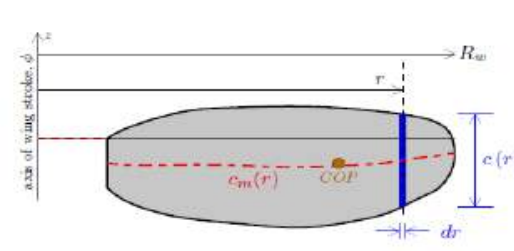

(c)

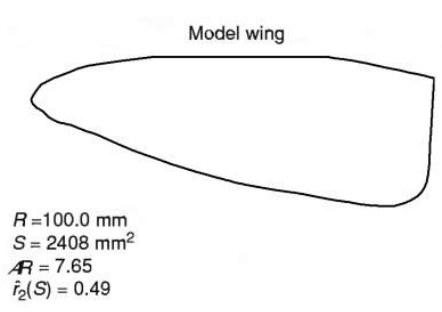

$\boldsymbol{A}=7.65$
$\hat{\hat{r}}_{2}(S)=0.49$

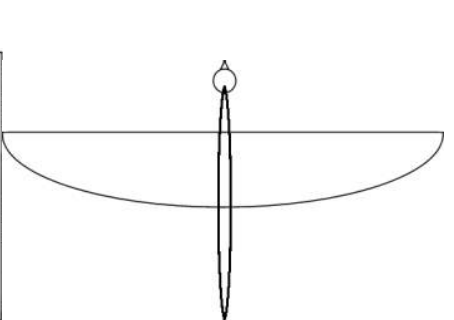

(f)

Figure 2. A generic semi-elliptical ornithopter's wing planform with the backdrop of various wing-planform geometries: from upper left, (a) Harmon (2008) wing model, (b)

Byl (2010) blade-element model, (c) Altshuler, Dudley, and Ellington (2004) wing

model, (d) pterosaur wing structure (Strang, 2009), (e) DeLaurier pterosaur-like ornithopter wing (2006), (f) a generic semi-elliptical wing planform (Djojodihardjo, Ramli, \& Wiriadidjaja, 2012b).

Based on Ellington's study (1984, 1999), the kinematics of flight produced by the generic wing (semi-elliptical wing) can be classified into the inclined stroke plane, 
where the resultant force produced by the wing can be separated into vertical and horizontal components, which are lift, thrust and drag, respectively throughout the upstroke and down-stroke cycle; the inclined stroke plane, where a large horizontal thrust component will be produced; and the vertical stroke plane.

\section{THEORETICAL DEVELOPMENT OF THE AERODYNAMICS OF BI-WING FLAPPING ORNITHOPTER}

Following the frame of thought elaborated in the previous section, several generic wing planforms are chosen in the present work as baseline geometries for the ornithopter wing biomimicry flapping mechanism, including the semi-elliptical wing (shown in Figure 2) with the backdrop of various wing-planform geometries utilized by various researchers.

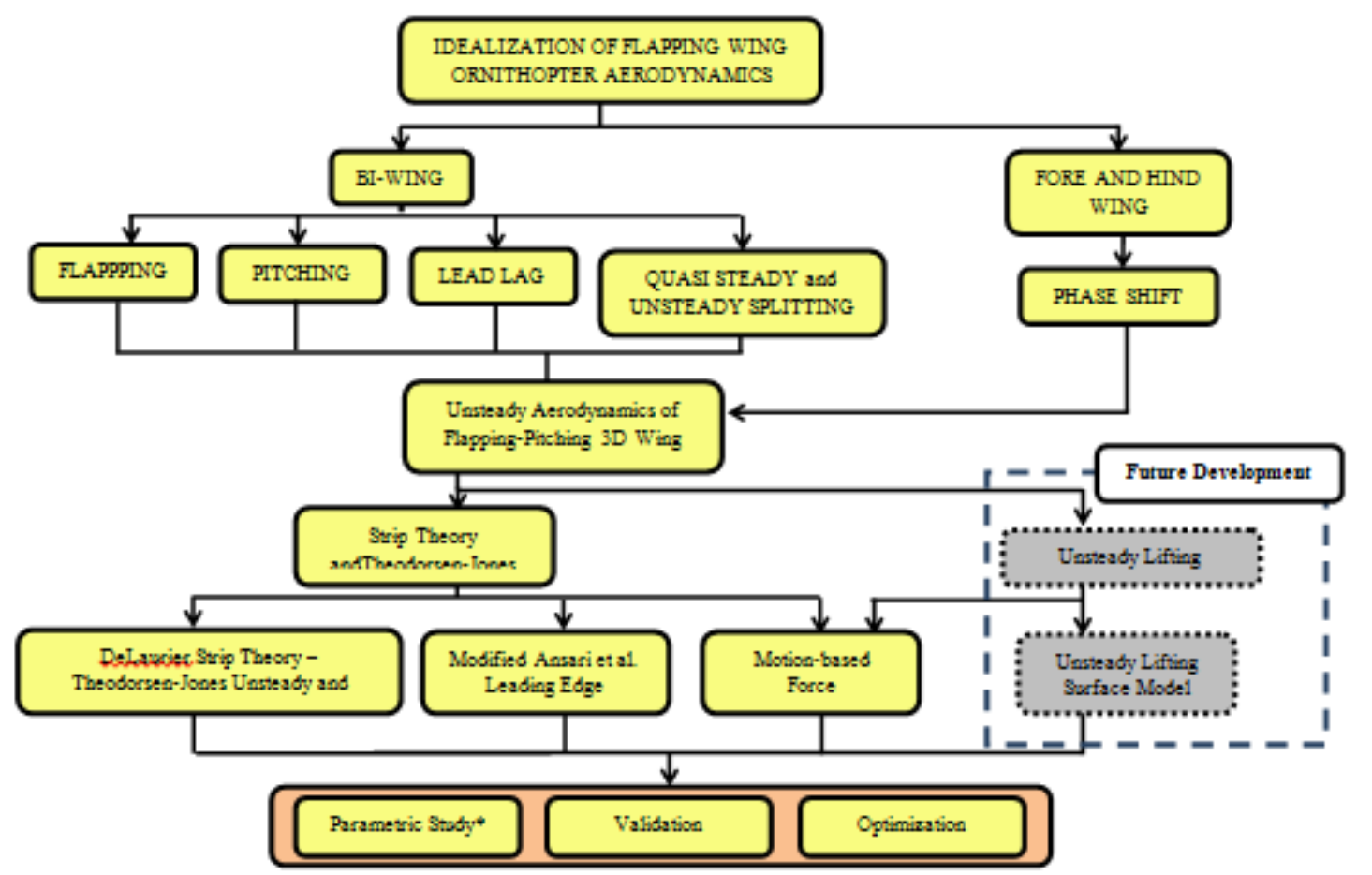

* Parametric Study to assist analysis, provide insight and optimization by inspection.

Figure 3. Ornithopter flapping wing aerodynamics computational scheme.

The present work resorts to an analytical approach to the flapping wing aerodynamic problem, which can be separated into quasi-steady and unsteady models. The quasi-steady model assumes that flapping frequencies are slow enough that shed wake effects are negligible, as in the pterosaur and medium- to large-sized birds, while the unsteady approach attempts to model the wake as with hummingbirds and insects. The quasi-steady approaches are classified into six techniques, which include momentum theory, blade element theory, hybrid momentum theory, lifting-line theory, thin-airfoil theory and lifting-surface theory (Smith, Wilkin, \& Williams, 1996). Two generic approaches are followed in the modeling of the aerodynamic calculation of the lift, drag and thrust generated by flapping wing motion. These are the computation of 
lift, drag and thrust generated by the pitching and flapping motion of a threedimensional rigid wing using strip theory and Jones' modified Theodorsen approach (1935) which incorporate Garrick's leading edge suction without spanwise twist and post-stall behavior as a simplified adaptation of DeLaurier's approach, and the computation of lift, drag and thrust generated by the pitching and flapping motion of a three-dimensional rigid wing in a structured method using strip theory and Jones' modified Theodorsen approach without camber, leading edge suction and post-stall behavior. The present study also addresses the contribution of wing pitching motion, flapping motion and coupled motion, as well as investigating the influence of pitch-flap phase lag, as a novel initiative, and parametric study for insight and optimization purposes by looking into the influence of the variation of the forward speed, flapping frequency and pitch-flap phase lag. The results of DeLaurier (1993), Byl (2010), Malik and Ahmad (2010) and Zakaria, Elshabka, Bayoumy, and AbdElhamid (2009) are used for validation. The computational logic in the present work is summarized in the flowchart exhibited in Figure 3.

\section{Computational Procedure}

The procedure basically follows the pitching-flapping motion of rigid wing that is a structured adaptation and simplification of the method adopted by DeLaurier (1993) and Harmon (2008). The flapping wing can have three distinct motions with respect to three axes as: a) Flapping, which is the up and down stroke motion of the wing, which produces the majority of the bird's power and has the largest degree of freedom; b) Feathering, which is the pitching motion of the wing and can vary along the span; c) Lead-lag, which is in-plane lateral movement of the wing.

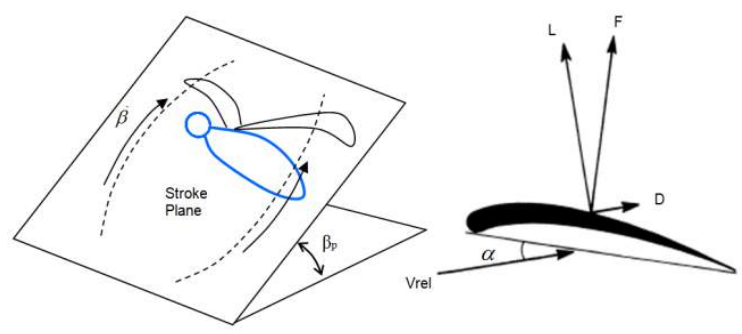

(a)
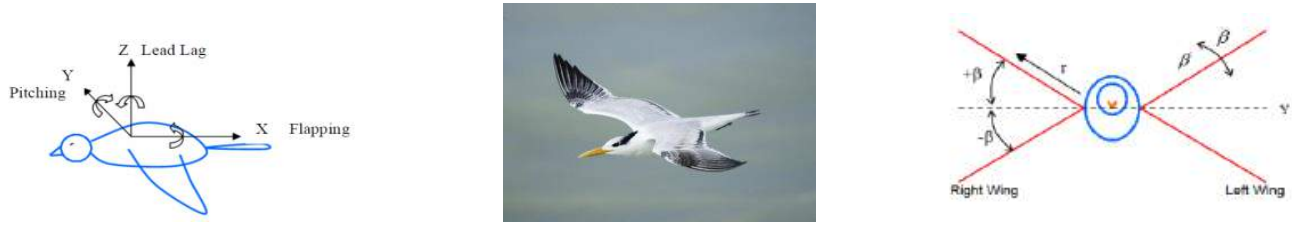

(b)

Figure 4. Angular movement of wing, adapted from Harmon (2008); the stroke plane is indicated in (a), an adaptation of Ellington's (1984) configuration (where $\beta_{\mathrm{p}}$ is the stroke plane angle).

The flapping angle $\beta$ varies as a sinusoidal function. $\beta$ and its rate and pitching angle $\theta$ are given by the following equations. The degree of freedom of the motion is depicted in Figure 4. 


$$
\beta(t)=\beta_{\max } \cos 2 \pi f t ; \dot{\beta}(t)=-2 \pi f \beta_{\max } \sin 2 \pi f t ; \theta(t)=\frac{y}{B} \theta_{0} \cos (2 \pi f t+\varphi)
$$

where $\theta_{0}$ is the maximum pitch angle, $\phi$ is the lag between the pitching and flapping angle and $\mathrm{r}$ is the distance along the span of the wing under consideration.

The vertical and horizontal components of relative wind velocity, as depicted in Figure 5, can be expressed as

$$
\begin{gathered}
V_{x}=U \cos \delta+(0.75 c \dot{\theta} \sin \theta) \\
V_{Z}=U \sin \delta+(-y \dot{\beta} \cos \beta)+(0.75 c \dot{\theta} \cos \beta)
\end{gathered}
$$

For horizontal flight, the flight path angle $\gamma$ is zero. Also, $0.75 c \dot{\theta}$ is the relative air effect of pitching rate $\dot{\theta}$ which is manifested at $75 \%$ of the chord length (DeLaurier, 1993). The relative velocity, relative angle between two velocity components $\psi$ and the relative angle of attack can be expressed as

$$
V=\sqrt{V_{x}^{2}+V_{z}^{2}} ; \psi=\tan ^{-1}\left(\frac{V_{z}}{V_{x}}\right) ; \text { and } \alpha=\psi+\theta
$$

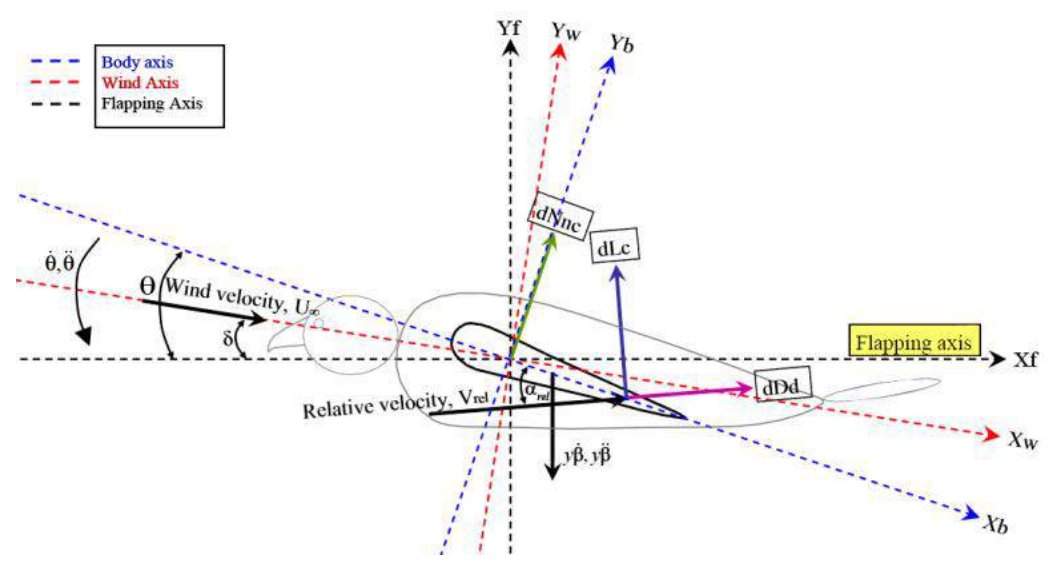

Figure 5. Forces on section of the wing.

The section lift coefficient due to circulation (Kutta-Joukowski condition, flat plate) is given by (DeLaurier, 1993)

$$
C_{l c}=2 \pi C(k) \sin \alpha
$$

The sectional lift $\mathrm{dL}_{\mathrm{c}}$ can then be calculated by

$$
d L_{c}=\frac{1}{2} \rho V^{2} C_{l c} c d y
$$

which should be integrated along the span to obtain the flapping-wing lift. Here $\mathrm{c}$ and $\mathrm{dr}$ are the chord length and width of the element of the wing under consideration, respectively. The apparent mass effect (momentum transferred by accelerating air to the 
wing) for the section is perpendicular to the wing, and acts at mid chord, and can be calculated as (Scherer, 1968; Harmon, 2008)

$$
d N_{n c}=-\frac{\rho \pi c^{2}}{4}(\dot{\theta} U+y \ddot{\beta} \cos \theta-0.5 \ddot{\theta}) d y
$$

The drag force has two components, profile drag $\mathrm{dD}_{\mathrm{p}}$ and induced drag $\mathrm{dD}_{\mathrm{i}}$. These are calculated as

$$
\begin{aligned}
d D_{p} & =\frac{1}{2} \rho V^{2} C_{d p} c d y \\
d D_{i} & =\frac{1}{2} \rho V^{2} C_{d i} c d y
\end{aligned}
$$

where the values for the drag coefficients $\mathrm{C}_{\mathrm{dp}}, \mathrm{C}_{\mathrm{df}}, \mathrm{C}_{\mathrm{di}}$ are assumed to be similar to those associated with basic geometrical cases (such as flat plate, airfoil with tabulated data and the like). $\mathrm{C}_{\mathrm{f}}$ is the skin friction coefficient for flat plate and to account for profile drag, a factor $\mathrm{K}$ is introduced (Harmon, 2008). A maximum value of $\mathrm{K}$ of 4.4 will be used (Scherer, 1968). $\mathrm{C}_{\mathrm{di}}$ is the induced drag coefficient, and e is the efficiency factor of the wing and is 0.8 for an elliptical wing. Total section drag is thus given by

$$
d D_{d}=d D_{p}+d D_{i}
$$

The circulatory lift $\mathrm{dL}_{\mathrm{c}}$, non-circulatory force $\mathrm{dN}_{\mathrm{nc}}$ and drag $\mathrm{dD}_{\mathrm{d}}$ for each section of the wing change direction at every instant during flapping. These forces in the vertical and horizontal directions will be resolved into those perpendicular and parallel to the forward velocity, respectively. The resulting vertical and horizontal components of the forces are given by

$$
\begin{aligned}
& d L=d L_{c} \cos \psi \cos \delta+d N_{n c} \cos (-\theta) \cos \beta \cos \delta+d D_{d} \sin \psi \cos \delta \\
& d T=d L_{c} \sin \psi \cos \delta+d N_{n c} \sin (-\theta) \cos \beta \cos \delta-d D_{d} \cos \psi \cos \delta
\end{aligned}
$$

and are calculated within one complete cycle, and averaged to get the total average lift and thrust of the ornithopter.

$\mathrm{C}^{\prime}(\mathrm{k}), \mathrm{F}^{\prime}(\mathrm{k})$ and $\mathrm{G}^{\prime}(\mathrm{k})$ relate to the well known Theodorsen function (Theodorsen, 1935; (Mueller, 2001) which are functions of reduced frequency k. A more sophisticated procedure (which will be added later on and introduced as a second method in the results and analysis subchapter) can be done by adding an expression for the leading edge suction of a two-dimensional airfoil to be applied on the present strip theory model (Garrick, 1936), introducing additional thrust:

$$
d T_{s}=\eta_{s} 2 \pi\left(\alpha^{\prime}+\bar{\theta}-\frac{1}{4} \frac{c \dot{\theta}}{U}\right)^{2} \frac{\rho U V}{2} c d y
$$

where $\alpha^{\prime}$ is a derivative of $\alpha$ and also the effect of downwash, $\mathrm{w}_{0} / \mathrm{U}$ which causes a local induced angle of attack, where it reduces lift (Kuethe, Schetzer, \& Chow, 1976). 


\section{RESULTS AND ANALYSIS}

The results below are obtained using the following wing geometry and parameters: wingspan $40 \mathrm{~cm}$, aspect ratio 6.2 , flapping frequency $7 \mathrm{~Hz}$, total flapping angle $60^{\circ}$, forward speed $6 \mathrm{~m} / \mathrm{s}$, maximum pitching angle $20^{\circ}$, and incidence angle $6^{\circ}$. The computational scheme developed has been validated satisfactorily. Two methods (procedures), the first method and second method, are shown for observance purposes on force production tolerance.
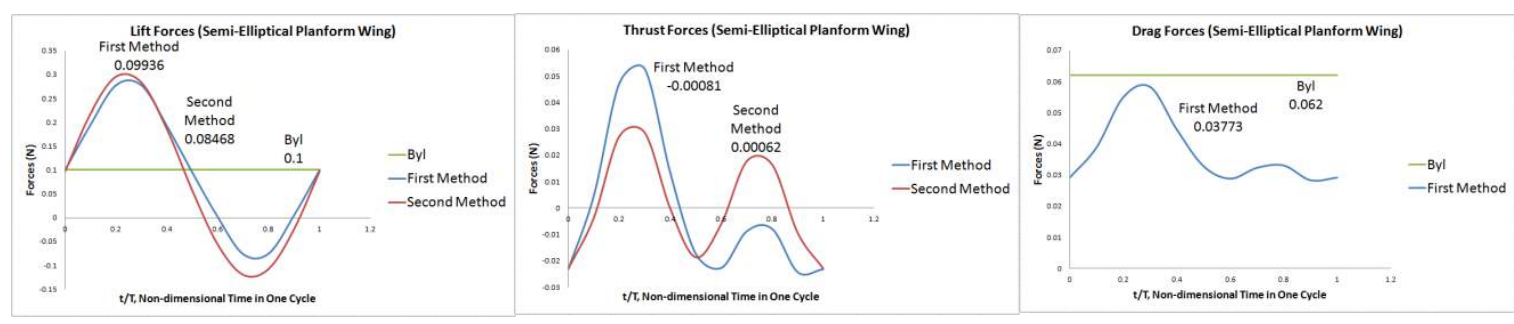

Figure 6. Lift and thrust forces (and drag force for the first computational procedure) with semi-elliptical planform wing; (a) first computational procedure; (b) second computational procedure.

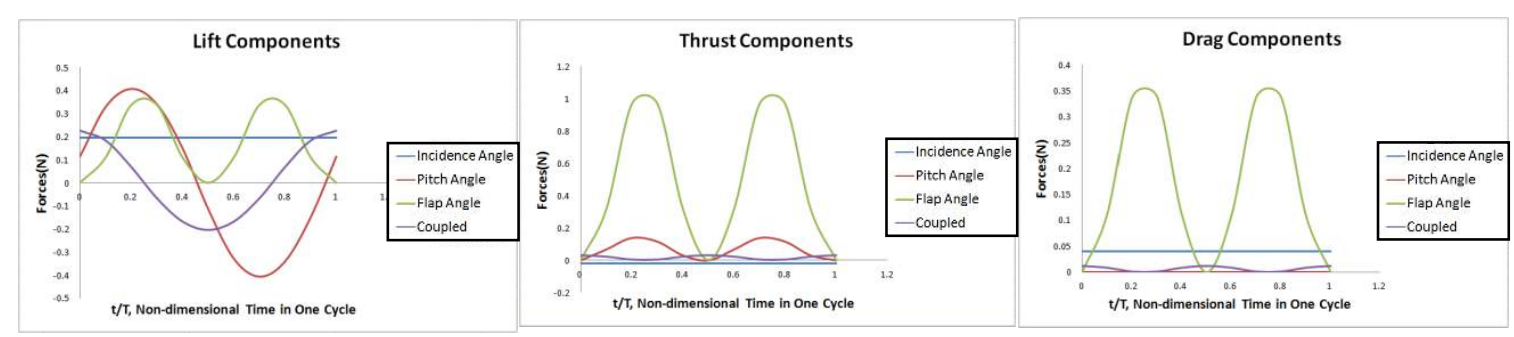

Wingbeat of $7 \mathrm{~Hz}$ corresponding to the particular worked out example

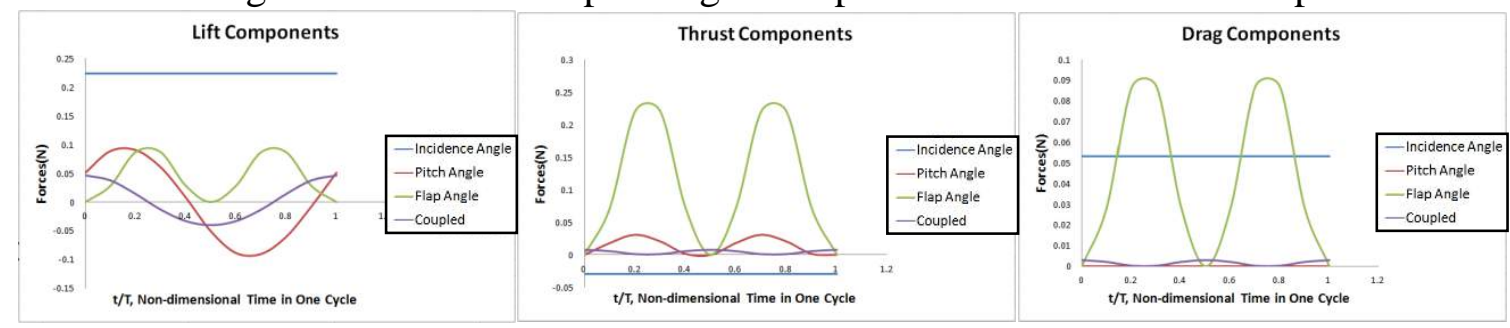

Wingbeat of $3.14 \mathrm{~Hz}$ corresponding to Pennycuick formula

Figure 7. The influence of individual contributions of the pitching-flapping motion and their phase lag on the flight performance. The influence of the flapping frequency is consistent, as illustrated in Figure 8.

A sample of such validation is shown in Figure 6, which was obtained using aerodynamic strip theory and Theodorsen-Jones modified formulations (Theodorsen, 1935; (Jones, 1940), where the geometry is similar to Harmon's (2008) and the parameters are relatively close to Harmon's (2008). The following assumptions were made: the pitching and flapping motions are in sinusoidal motion, and the upstroke and downstroke phases have equal time duration. There is an incidence angle, which is $6^{\circ}$ and there is no flight path angle. The phase lag was assumed to be fixed at $90^{\circ}$. Harmon's (2008) example did not incorporate the leading edge suction, wake capture 
and dynamic stall. As Figure 6 indicates, the computational results using the present second generic computational procedure have comparable agreement to the measured results by Harmon (2008) and first generic method (Djojodihardjo et al., 2012b). The average values for lift per flapping cycle calculated using the first and second computational procedure are comparable, both for rectangular and semi-elliptical planforms. Agreement with Byl's (2010) value of lift per flapping cycle for the modified elliptical planform is only qualitative, which is understandable given the simplicity of our models. The average lift per flapping cycle computed using the second computational procedure for DeLaurier's pterosaur wing is in excellent agreement with those obtained by both DeLaurier and Zakaria et al., while for the thrust, the present second computational procedure result agrees with (Djojodihardjo, Ramli, \& Wiriadidjaja, 2012a; Zakaria et al., 2009). As elaborated there, the average thrust per flapping cycle calculated using the first computational procedure is close to that obtained by Malik and Ahmad (2010). Another study is carried out to investigate the influence of individual contributions of the pitching-flapping motion and their phase lag on the flight performance. The calculation is performed on a rectangular wing. Results obtained as exhibited in Figure 7 show that for the lift, the pitching angle dominates the force, while for the thrust, it is the flapping angle. The drag is also dominated by the flapping effect.

\section{PARAMETRIC STUDY OF BI-WING FLAPPING ORNITHOPTER}

A parametric study is carried out to assess the influence of some flapping wing motion parameters on the flight performance desired. The study considers the following parameters: the effect of forward speed, the effect of flapping frequency, the effect of lag angle, the effect of angle of incidence and the effect of total flapping angle. The results are exhibited in Figure 8.

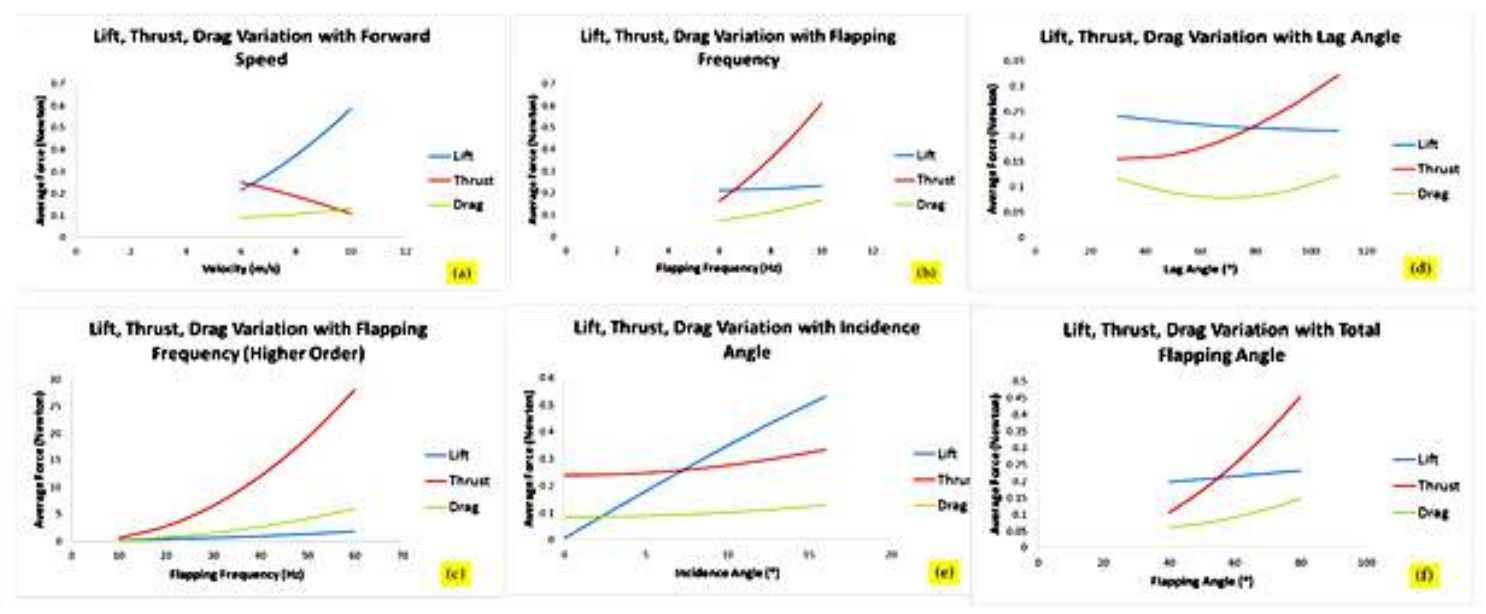

Figure 8. Parametric study on the influence of forward speed (a), flapping frequency (b, c), flapping-pitching phase lag (d), angle of incidence (e) and total flapping angle (f) on cyclic lift, drag and thrust (for a wing of rectangular planform).

An interesting result is shown in Figures 8 (b) and (c), where the wingbeat frequency has been varied and the thrust is consistently increased with the increase of the wingbeat frequency, while the lift increases only slightly. If reference is made to Pennycuick's formula (1) and Tucker's formula (Tucker, 1987) to correlate the wing- 
span and wing area of birds, the present ornithopter model operating frequencies as anticipated in Figure 8 are close to the operating flapping frequency values of the selected birds shown in Table 3.

\section{QUAD FLAPPING WING MICRO AIR VEHICLE}

Following a similar kinematic and aerodynamic model and aerodynamic computational scheme to that elaborated in the previous sections, a computational study is carried out for a quad-wing flapping ornithopter, using similar dimensions to those of the bi-wing flapping ornithopter.
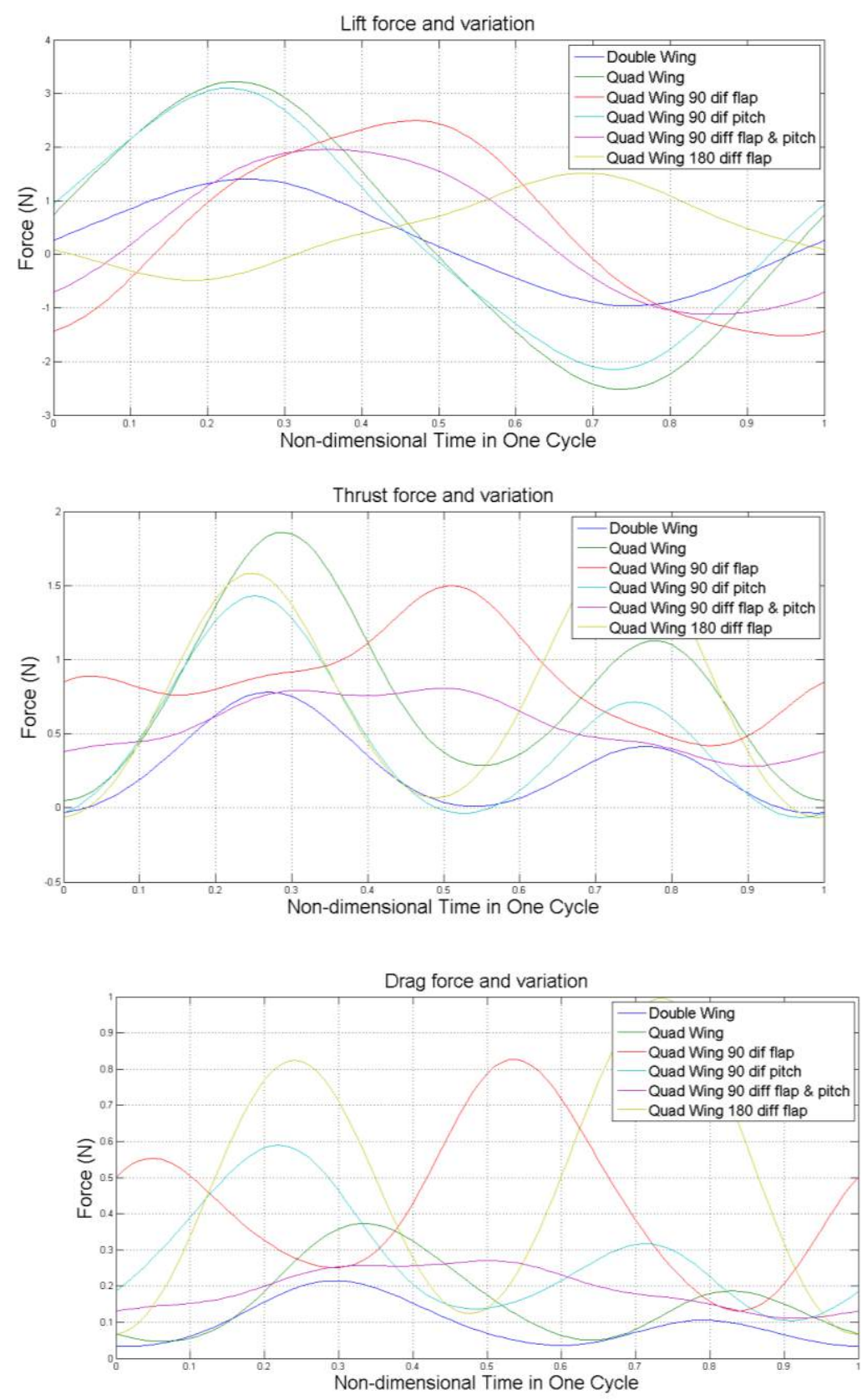

Figure 9. Lift, thrust and drag forces comparison with each specification. 
The wing dimensions are such that performance comparison between the biwing and quad-wing ornithopter can be made, as the total wing area should be similar for both. The influence of individual contributions of the pitching-flapping motion and their phase lag on the flight performance is carefully modeled and investigated. Without loss of generality, for simplicity the calculation is also performed on the rectangular wing. The results obtained as shown in Figure 9 exhibit the lift for various scenarios involving phase combinations between flapping and pitching motions of the individual contribution of the fore- and hind-wings. Table 2 summarizes the average forces of the selected scenarios.

Table 2. Average forces for all specifications.

\begin{tabular}{llllll}
\hline $\begin{array}{l}\text { Average } \\
\text { force }\end{array}$ & Bi-wing & Quad-wing & $\begin{array}{l}\text { Quad- } \\
\text { wing, } \\
\text { flapping } \\
90^{\circ} \\
\text { different } \\
\text { phase }\end{array}$ & $\begin{array}{l}\text { Quad-wing, } \\
\text { pitching } \\
\text { different } \\
\text { phase }\end{array}$ & $\begin{array}{l}\text { Quad- } \\
\text { wing, } \\
\text { flapping } \\
\text { and } \\
\text { pitching } \\
90^{\circ} \\
\text { different } \\
\text { phase }\end{array}$ \\
& & & & 0.4096 \\
& & & & 0.1928 \\
& & & 0.4391 & 0.4378 & 0.5580 \\
\hline Lift (N) & 0.2108 & 0.3503 & 0.4270 & 0.2817 & \\
Drag (N) & 0.0961 & 0.1629 & 0.8770 & 0.4793 & \\
Thrust & 0.2768 & 0.7902 & & & \\
(N) & & & & & \\
\hline
\end{tabular}

\section{GENERAL OBSERVATION}

The computational results for simplified modeling of both bi-wing and quad-wing ornithopters are meant for better understanding of the key elements that produce lift and thrust forces for these ornithopters, as well as a guideline for developing a simple experimental model that can be easily built. A more sophisticated computational and experimental model can be built in a progressive fashion, by superposing other key features. To gain better insight into the kinematic and aerodynamic modeling of bi-wing and quad-wing ornithopters, comparison will be made between the basic characteristics and performance of selected ornithopter models and those of selected real birds and insects. For this purpose, Table 3 compares the basic performance of ornithopter and entomopter models, and birds and insects. Table 3 exhibits the ratio of the lift per cycle calculated using the present simplified computational model and those obtained by other investigators; for comparison, the weight per wing-span of a selected sample of birds is also exhibited. Although the comparison is by no means rigorous, it may shed some light on how the geometrical modeling and the flapping motion considered in the computational model may contribute to the total lift produced and how further refinement could be synthesized. 
Table 3.Comparison of basic performance of ornithopter and entomopter models, and birds and insects.

For birds: applicable Tucker's formula: $*(S=0.260 b-0.020), * *(S=0.335 b-0.041), * * *(S=0.112 b+0.019)$. Also, the birds are assumed in to be in hovering motion, where lift is equal to the weight of the bird.

\begin{tabular}{|c|c|c|c|c|c|}
\hline $\begin{array}{l}\text { ORNITHOPTER } \quad \& \\
\text { ENTOMOPTER } \\
\text { MAV MODEL } \\
\end{array}$ & Present Method & Malik \& Ahmad & $\begin{array}{l}\text { Byl's hummingbird-scale } \\
\text { robot }\end{array}$ & $\begin{array}{l}\text { DeLaurier pterosaur } \\
\text { model }\end{array}$ & Kesel's Dragonfly \\
\hline Wingspan & $0.4 \mathrm{~m}$ & $0.4 \mathrm{~m}$ & $0.16 \mathrm{~m}$ & $5.4864 \mathrm{~m}$ & $0.558 \mathrm{~m}$ \\
\hline Average Lift Cycle & $0.099361 \mathrm{~N}$ & $0.1705 \mathrm{~N}$ & $0.1 \mathrm{~N}$ & $133 \mathrm{~N}$ & $0.1186 \mathrm{~N}$ \\
\hline & & $-\infty$ & & IIII & 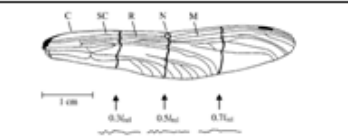 \\
\hline $\begin{array}{l}\text { Lift to Wingspan } \\
\text { Ratio }\end{array}$ & $0.2484 \mathrm{~N} / \mathrm{m}$ & $0.4263 \mathrm{~N} / \mathrm{m}$ & $0.6250 \mathrm{~N} / \mathrm{m}$ & $24.2418 \mathrm{~N} / \mathrm{m}$ & $0.2125 \mathrm{~N} / \mathrm{m}$ \\
\hline BIRD \& INSECT & Turkey Vulture & Red-tailed Hawk & Bald Eagle & Peregrine Falcon & Sympetrum Sanguineum \\
\hline Length & $67 \mathrm{~cm}$ & $49 \mathrm{~cm}$ & $79 \mathrm{~cm}$ & $46 \mathrm{~cm}$ & $0.03899 \mathrm{~cm}$ \\
\hline Wingspan & $171 \mathrm{~cm}$ & $125 \mathrm{~cm}$ & $203 \mathrm{~cm}$ & $116 \mathrm{~cm}$ & $\begin{array}{l}0.0557 \mathrm{~cm} \text { (forewing) } \\
0.0538 \mathrm{~cm} \text { (hindwing) }\end{array}$ \\
\hline Mass & $1.8 \mathrm{~kg}$ & $1.082 \mathrm{~kg}$ & $4.3 \mathrm{~kg}$ & $0.952 \mathrm{~kg}$ & $0.122 \mathrm{~g}$ \\
\hline $\begin{array}{l}\text { Lift to Wingspan } \\
\text { Ratio (N/m) }\end{array}$ & $\frac{18(\mathrm{~N})}{1.71(\mathrm{~m})}=10.5$ & $\frac{10.82(\mathrm{~N})}{1.25(\mathrm{~m})}=8.656$ & $\frac{43(\mathrm{~N})}{2.03(\mathrm{~m})}=21.182$ & $\frac{9.52(\mathrm{~N})}{1.16(\mathrm{~m})}=8.206$ & $\begin{array}{l}\frac{1.221 \times 10^{-3}(\mathrm{~N})}{0.0557 \times 10^{-2}(\mathrm{~m})}=2.192 \text { (forewing) } \\
\frac{1.221 \times 10^{-3}(\mathrm{~N})}{0.0538 \times 10^{-2}(\mathrm{~m})}=2.270 \text { (hindwing) }\end{array}$ \\
\hline $\begin{array}{l}\text { Lift to Wing Area } \\
\text { Ratio }\left(N / m^{2}\right)\end{array}$ & $\frac{18(\mathrm{~N})}{0.425\left(\mathrm{~m}^{2}\right)}=42.353$ & $\frac{10.82(\mathrm{~N})}{0.305\left(\mathrm{~m}^{2}\right)}=35.475$ & $\frac{43(\mathrm{~N})}{0.639\left(\mathrm{~m}^{2}\right)}=67.293$ & $\frac{9.52(\mathrm{~N})}{0.149\left(\mathrm{~m}^{2}\right)}=43.758$ & $\begin{array}{l}\frac{1.221 \times 10^{-3}(\mathrm{~N})}{327.87 \times 10^{-6}\left(\mathrm{~m}^{2}\right)}=3.724 \text { (fore wing) } \\
\frac{1.221 \times 10^{-3}(\mathrm{~N})}{413.45 \times 10^{-6}\left(\mathrm{~m}^{2}\right)}=2.953 \text { (hind wing) }\end{array}$ \\
\hline $\begin{array}{l}\text { Wing Area } \\
\text { following Tucker's } \\
\text { Formula (1987) }\end{array}$ & $0.425 \mathrm{~m}^{2}$ & $0.305 \mathrm{~m}^{2}$ & $0.639 \mathrm{~m}^{2}$ & $0.149 \mathrm{~m}^{2}$ & $\begin{array}{l}327.87 \mathrm{~mm}^{2} \text { (forewing) } \\
413.45 \mathrm{~mm}^{2} \text { (hindwing) }\end{array}$ \\
\hline $\begin{array}{l}\text { Wing beat } \\
\text { Frequency }\end{array}$ & $2.79 \mathrm{~Hz}$ & $3.50 \mathrm{~Hz}$ & $2.84 \mathrm{~Hz}$ & $4.32 \mathrm{~Hz}$ & $\begin{array}{l}38.7 \mathrm{~Hz} \text { (forewing) } \\
39.2 \mathrm{~Hz} \text { (hindwing) }\end{array}$ \\
\hline
\end{tabular}

\section{CONCLUSIONS}

The present work has been performed to assess the effect of flapping-pitching motion with pitch-flap phase lag in the flight of an ornithopter. In this conjunction, a computational model has been developed following the generic two-dimensional unsteady theory of Theodorsen with modifications to account for three-dimensional and viscous effects, leading edge suction and post-stall behavior. The study is carried out on rectangular and semi-elliptical wing planforms. The results have been compared and validated with results from other researchers with a similar unsteady aerodynamic approach and general physical data. Within the limitations of the physical assumptions, these results indicate encouraging qualitative agreement or better. For the bi-wing flapping ornithopter, judging from the lift per unit span, the present flapping-wing model performance is comparable to those studied by Byl (2010), while DeLaurier (1993) pterosaur model is of a larger order of magnitude and comparable to a bald eagle. The analysis and simulation by splitting the flapping and pitching motion shows that: (a) the lift is dominantly produced by the pitching motion, since the relative airflow effect prevailed along $75 \%$ of the chord length; (b) the thrust is dominated by flapping motion. The vertical component of relative velocity increases significantly compared to the horizontal components, which causes the force vector produced by the flapping-pitching motion to be directed towards the horizontal axis (thrust axis); (c) the drag is dominated by the flapping motion, due to higher relative velocity as well as higher induced drag due to circulation. 
For the quad-wing ornithopter, at the present stage, the simplified computational model adopted verified the gain in lift obtained as compared to the bi-wing flapping ornithopter, in particular with the possibility of designing the appropriate phase lag between the flapping and pitching motion of the fore- and hind-wings. A structured approach has been followed to assess the effect of different design parameters on lift, thrust, and drag of an ornithopter, as well as the individual contribution of each of the components of the flapping motion. These results lend support to the utilization of the generic modeling adopted in the synthesis of a flight model, although a more refined approach should be further developed. Various approaches for ornithopter aerodynamic modeling could be followed, such as the incorporation of other parameters, the use of a more refined blade element, CFD or lifting surface methods. In retrospect, a generic physical and computational model based on simple kinematics and basic aerodynamics of a flapping-wing ornithopter has been demonstrated to be capable of revealing the basic characteristics of a flapping-wing MAV and can be utilized for its further development.

\section{ACKNOWLEDGMENTS}

The authors would like to thank Universiti Putra Malaysia (UPM) for granting Research University Grant Scheme (RUGS) Project Code: 9378200, under which the present research is carried out.

\section{REFERENCES}

Altshuler, D. L., Dudley, R., \& Ellington, C. P. (2004). Aerodynamic forces of revolving hummingbird wings and wing models. Journal of zoology, 264(4), 327-332.

Ansari, S., Żbikowski, R., \& Knowles, K. (2006). Aerodynamic modelling of insect-like flapping flight for micro air vehicles. Progress in Aerospace Sciences, 42(2), 129-172.

Byl, K. (2010). A passive dynamic approach for flapping-wing micro-aerial vehicle control. Paper presented at the ASME 2010 Dynamic Systems and Control Conference.

DeLaurier, J. D. (1993). An aerodynamic model for flapping-wing flight. Aeronautical Journal, 97(964), 125-130.

Dickinson, M. H., Lehmann, F.-O., \& Sane, S. P. (1999). Wing rotation and the aerodynamic basis of insect flight. Science, 284(5422), 1954-1960.

Djojodihardjo, H., Ramli, A. S. S., \& Wiriadidjaja, S. (2012a). Generic modeling and parametric study of flapping wing micro-air-vehicle. Applied Mechanics and Materials, 225, 18-25.

Djojodihardjo, H., Ramli, A. S. S., \& Wiriadidjaja, S. (2012b). Kinematic and aerodynamic modelling of flapping wing ornithopter. Procedia Engineering, 50, 848-863.

Ellington, C. P. (1984). The aerodynamics of hovering insect flight. I. The quasi-steady analysis. Philosophical Transactions of the Royal Society of London. B, Biological Sciences, 305(1122), 1-15.

Ellington, C. P. (1999). The novel aerodynamics of insect flight: Applications to microair vehicles. Journal of Experimental Biology, 202(23), 3439-3448.

Garrick, I. E. (1936). Propulsion of a flapping and oscillating aerofoil (Vol. 567): NACA Report 
Harmon, R. L. (2008). Aerodynamic modelling of a flapping membrane wing using motion tracking experiments. (MSc Thesis), University of Maryland.

Ho, S., Nassef, H., Pornsinsirirak, N., Tai, Y.-C., \& Ho, C.-M. (2003). Unsteady aerodynamics and flow control for flapping wing flyers. Progress in Aerospace Sciences, 39(8), 635-681.

Jackowski, Z. J. (2009). Design and construction of an autonomous ornithopter. Massachusetts Institute of Technology.

Jones, R. T. (1940). The unsteady lift of a wing of finite aspect ratio (Vol. 681): NACA Report

Kuethe, A. M., Schetzer, J. D., \& Chow, C. Y. (1976). Foundations of aerodynamics: John Wiley.

Malik, M. A., \& Ahmad, F. (2010). Effect of different design parameters on lift, thrust, and drag of an ornithopter. Paper presented at the Proceedings of the World Congress on Engineering, London, U.K.

Maybury, W. J., \& Lehmann, F.-O. (2004). The fluid dynamics of flight control by kinematic phase lag variation between two robotic insect wings. Journal of Experimental Biology, 207(26), 4707-4726.

Mueller, T. J. (2001). Fixed and flapping wing aerodynamics for micro air vehicle applications. Reston, VA: AIAA Publications.

Nicholson, B., Page, S., Dong, H., \& Slater, J. (2007). Design of a flapping quadwinged micro air vehicle. Paper presented at the American Institute of Aeronautics and Astronautics USA.

Prosser, D., Basrai, T., Dickert, J., Ratti, J., Crassidis, A., \& Vachtsevanos, G. (2011). Wing kinematics and aerodynamics of a hovering flapping micro aerial vehicle. Paper presented at the Aerospace Conference, 2011 IEEE.

Prosser, D. T. (2011). Flapping wing design for a dragon-fly like mav. (MSc Thesis), Rochester Institute of Technology.

Ratti, J. (2011). Qv-the quad winged, energy efficient, six degree of freedom capable micro air vehicle. (PhD thesis), Georgia Institute of Technology.

Shyy, W., Berg, M., \& Ljungqvist, D. (1999). Flapping and flexible wings for biological and micro air vehicles. Progress in Aerospace Sciences, 35(5), 455-505.

Smith, M., Wilkin, P., \& Williams, M. (1996). The advantages of an unsteady panel method in modelling the aerodynamic forces on rigid flapping wings. The journal of experimental biology, 199(5), 1073-1083.

Strang, K. A. (2009). Efficient flapping flight of pterosaurs. (PhD Thesis), Stanford University.

Tucker, V. A. (1987). Gliding birds: The effect of variable wing span. Journal of Experimental Biology, 133, 35-58.

Zakaria, M. Y., Elshabka, A. M., Bayoumy, A. M., \& AbdElhamid, O. E. (2009). Numerical aerodynamic characteristics of flapping wings. Paper presented at the 13th International Conference on Aerospace Sciences and Aviation Technology. 


\section{Nomenclature}

c chord

$\mathrm{C}(\mathrm{k})$ Theodorsen function

$\mathrm{C}_{\mathrm{df}} \quad$ drag coefficient due to skin friction

$\mathrm{C}_{\mathrm{dp}} \quad$ profile drag coefficient

$\mathrm{C}_{\mathrm{di}} \quad$ induced drag coefficient

$\mathrm{C}_{\mathrm{lc}} \quad$ circulatory lift coefficient

$\mathrm{dD}_{\mathrm{d}} \quad$ sectional total drag

$\mathrm{dD}_{\mathrm{f}} \quad$ sectional friction drag

$\mathrm{dD}_{\mathrm{p}} \quad$ sectional profile drag

$\mathrm{dD}_{\mathrm{i}} \quad$ sectional induced drag

dL sectional instantaneous lift

$\mathrm{dL}_{\mathrm{c}} \quad$ sectional circulatory lift

$\mathrm{dN}_{\mathrm{nc}} \quad$ sectional apparent mass effect

$\mathrm{dT}_{\mathrm{s}} \quad$ sectional additional thrust due to leading edge suction

dy width of sectional strip under

consideration

f wingbeat frequency

$\mathrm{y} \quad$ distance along the span of $i$ th strip

$\mathrm{t}$ time
$\mathrm{V}_{\mathrm{x}} \quad$ velocity component along $\mathrm{x}$-axis

$\mathrm{V}_{\mathrm{z}} \quad$ velocity component along $\mathrm{z}$-axis

$\mathrm{V}$ relative velocity

$\mathrm{w}_{0} \quad$ downwash velocity at $3 / 4$-chord location

$\rho \quad$ air density

$\beta \quad$ flapping angle

$\beta_{\max } \quad$ maximum flapping angle

$\beta_{\mathrm{p}} \quad$ stroke plane angle

$\dot{\beta} \quad$ flapping rate

$\theta \quad$ pitching angle

$\dot{\theta} \quad$ pitching rate

$\theta_{0} \quad$ maximum pitch angle

$\phi \quad$ lag between pitching and flapping angle

$\delta \quad$ incidence angle

$\gamma \quad$ flight path angle

$\psi \quad$ relative angle between two velocity components

$\alpha \quad$ relative angle of attack

$\eta_{\mathrm{s}} \quad$ efficiency coefficient 